\title{
Post-translational regulation of P2X receptor channels: modulation by phospholipids
}

\author{
Louis-Philippe Bernier ${ }^{1}$, Ariel R. Ase ${ }^{2}$ and Philippe Séguéla ${ }^{2 *}$ \\ ' Department of Psychiatry, Brain Research Centre, University of British Columbia, Vancouver, BC, Canada \\ ${ }^{2}$ Department of Neurology and Neurosurgery, Alan Edwards Centre for Research on Pain, Montreal Neurological Institute, McGill University, Montréal, QC, Canada
}

\section{Edited by:}

Rashid Giniatullin, University of Eastern Finland, Finland

\section{Reviewed by:}

Hana Zemkova, Academy of Sciences of the Czech Republic, Czech Republic Peter Illes, University of Leipzig, Germany

\section{*Correspondence:}

Philippe Séguéla, Department of Neurology and Neurosurgery, Alan

Edwards Centre for Research on Pain, Montreal Neurological Institute, McGill University, 3801 University, Suite 778, Montréal, H3A 2B4 OC, Canada e-mail:philippe.seguela@mcgill.ca
P2X receptor channels mediate fast excitatory signaling by ATP and play major roles in sensory transduction, neuro-immune communication and inflammatory response. P2X receptors constitute a gene family of calcium-permeable ATP-gated cation channels therefore the regulation of $\mathrm{P} 2 \mathrm{X}$ signaling is critical for both membrane potential and intracellular calcium homeostasis. Phosphoinositides $\left(P I P_{n}\right)$ are anionic signaling phospholipids that act as functional regulators of many types of ion channels. Direct $\mathrm{PIP}_{\mathrm{n}}$ binding was demonstrated for several ligand- or voltage-gated ion channels, however no generic motif emerged to accurately predict lipid-protein binding sites. This review presents what is currently known about the modulation of the different P2X subtypes by phospholipids and about critical determinants underlying their sensitivity to PIP $_{n}$ levels in the plasma membrane. All functional mammalian P2X subtypes tested, with the notable exception of $\mathrm{P} 2 \mathrm{X} 5$, have been shown to be positively modulated by $P I P_{n}$, i.e., homomeric $\mathrm{P} 2 \mathrm{X} 1, \mathrm{P} 2 \mathrm{X} 2, \mathrm{P} 2 \mathrm{X} 3, \mathrm{P} 2 \mathrm{X} 4$, and $\mathrm{P} 2 \mathrm{X} 7$, as well as heteromeric $\mathrm{P} 2 \mathrm{X} 1 / 5$ and $\mathrm{P} 2 \mathrm{X} 2 / 3$ receptors. Based on various results reported on the aforementioned subtypes including mutagenesis of the prototypical $\mathrm{PIP}_{\mathrm{n}}$-sensitive $\mathrm{P} 2 \mathrm{X} 4$ and $\mathrm{PIP}_{\mathrm{n}}$-insensitive $\mathrm{P} 2 \mathrm{X} 5$ receptor subtypes, an increasing amount of functional, biochemical and structural evidence converges on the modulatory role of a short polybasic domain located in the proximal C-terminus of P2X subunits. This linear motif, semi-conserved in the P2X family, seems necessary and sufficient for encoding direct modulation of ATP-gated channels by PIP $\mathrm{n}_{\mathrm{n}}$. Furthermore, the physiological impact of the regulation of ionotropic purinergic responses by phospholipids on pain pathways was recently revealed in the context of native crosstalks between phospholipase C (PLC)-linked metabotropic receptors and $\mathrm{P} 2 \mathrm{X}$ receptor channels in dorsal root ganglion sensory neurons and microglia.

Keywords: P2X receptors, ligand-gated channel, purine nucleotides, PIP2, phospholipids, pain, calcium, phospholipases
P2X receptor channels are involved in a wide variety of physiological processes ranging from sensory transduction to neuroimmune interactions to synaptic modulation. Upon binding to their agonist ATP, conformational changes induce the opening of a non-selective cation channel, impacting cellular physiology through membrane depolarization and calcium influx (North, 2002). This process is tightly controlled by various allosteric regulatory mechanisms, some acting on extracellular or transmembrane regions of the channel subunits, as is the case for metals, pH, divalent cations or alcohols (Coddou et al., 2011). On the other hand, several mechanisms of posttranslational regulation are known to affect the efficacy of $\mathrm{P} 2 \mathrm{X}$ activation by interacting with the intracellular $\mathrm{N}$ - or C-terminal tails of the subunits. Among them, plasma membrane-bound lipids such as phosphoinositides $\left(\mathrm{PIP}_{\mathrm{n}}\right)$ were shown to have an important functional impact on $\mathrm{P} 2 \mathrm{X}$ receptors, emerging as cofactors necessary for full channel activity. Here, we will review the recent evidence describing PIP $_{n}$-dependent functional modulation for various members of the $\mathrm{P} 2 \mathrm{X}$ receptor channel family, the molecular determinants of the protein-lipid interaction as well as the impact of this novel regulatory mechanism at the cellular level.

\section{FUNCTIONAL INTERACTIONS BETWEEN PIP ${ }_{\mathrm{n}}$ AND ION CHANNELS}

PIP $_{n}$ are composed of two fatty acid chains esterified to a glycerol backbone, attached to a myo-inositol ring forming a polar head group. Poly-PIP $\mathrm{n}_{\mathrm{n}}$ are synthesized through phosphorylations by selective PI kinases and are found in low abundance in cellular membranes, with phosphatidylinositol 4,5-bisphosphate $\left(\mathrm{PI}(4,5) \mathrm{P}_{2} ; \mathrm{PIP}_{2}\right)$ being the most common, but only representing 1\% of total cellular acidic lipids (Toker, 1998; Prestwich, 2004). PIP $_{n}$ are classically viewed as critical players in ubiquitous intracellular signaling pathways. Notably, activation of phospholipase $\mathrm{C}$ (PLC) catalyses the hydrolysis of $\mathrm{PIP}_{2}$, giving rise to inositol trisphosphate $\left(\mathrm{IP}_{3}\right)$ and diacylglycerol (DAG), triggering multiple signaling cascades (Berridge, 1993; Monserrate and York, 2010). The different species of PIP $\mathrm{P}_{\mathrm{n}}$ can also serve 
as membrane-bound anchors to various proteins, acting as a localization tag to specific organelles (Doughman et al., 2003; Heo et al., 2006). A third major signaling role of membrane $\mathrm{PIP}_{\mathrm{n}}$ involves their direct functional regulation of integral membrane proteins (Suh and Hille, 2005; Gamper and Shapiro, 2007; Logothetis et al., 2010). Several families of channels and transporters have been demonstrated to be sensitive to PIP $_{n}$ levels, among them are transient receptor potential (TRP) channels (Rohacs, 2007), inward-rectifier potassium channels (Kir) (Huang et al., 1998; Logothetis et al., 2007), KCNQ voltage-gated potassium channels (Hernandez et al., 2008b), cyclic nucleotidegated (CNG) channels (Womack et al., 2000), epithelial sodium channels (ENaC; Kunzelmann et al., 2005), calcium releaseactivated calcium (CRAC) channels (Korzeniowski et al., 2009) and $\mathrm{P} 2 \mathrm{X}$ receptor channels. Whereas direct protein-lipid binding was demonstrated for some of these families including P2X receptors, no consensus amino acid sequence has been defined to predict $\mathrm{PIP}_{\mathrm{n}}$ binding to channels and transporters. However, several lines of evidence indicate that positive residues located on intracellular portions of the protein electrostatically interact with the negative head group of PIP $_{n}$ to mediate the functional interaction (Rosenhouse-Dantsker and Logothetis, 2007; Whorton and Mackinnon, 2011).

\section{FUNCTIONAL REGULATION OF P2X RECEPTORS BY PIP ${ }_{n}$ P2X1}

The initial observation of $\mathrm{PIP}_{\mathrm{n}}$-dependence for the $\mathrm{P} 2 \mathrm{X} 1$ receptor subtype came from inside-out macropatch recordings in Xenopus oocytes expressing the receptor. Under this experimental condition, sequestration of $\mathrm{PI}(4,5) \mathrm{P}_{2}$ by application of polylysine led to a current rundown, which could further be rescued by the addition of a soluble $\mathrm{PI}(4,5) \mathrm{P}_{2}$ analog to the intracellular side of the membrane (Zhao et al., 2007). The regulatory role of PIP $\mathrm{n}_{\mathrm{n}}$ on $\mathrm{P} 2 \mathrm{X} 1$ channel function was later confirmed when it was shown that blocking PI4 kinase (PI4K) activity negatively modulated P2X1 current amplitude and recovery from desensitization in whole-cell recordings performed on Xenopus oocytes expressing P2X1 (Bernier et al., 2008b). Current activation and desensitization rates were also slowed by $\mathrm{PI}(4,5) \mathrm{P}_{2}$ depletion, suggesting a modulatory effect of the lipids on channel gating kinetics. However, PI3 kinase (PI3K) blockade did not affect P2X1 responses, indicating a prevalent role of $\mathrm{PI}(4,5) \mathrm{P}_{2}$, as confirmed by the results showing a complete recovery of current kinetics and amplitude upon intracellular application of a soluble $\mathrm{PI}(4,5) \mathrm{P}_{2}$ analog in the recorded oocyte following pharmacological depletion. A direct interaction between the proximal C-terminal region of P2X1 and various PIP $_{n}$ was shown by the binding of fusion proteins containing the region of interest to phospholipid species including $\mathrm{PI}(4,5) \mathrm{P}_{2}$ coated on nitrocellulose membranes (PIP strips). Mutating intracellular C-terminal basic residues into neutral glutamine (K359Q, K364Q) decreased the interaction affinity in this in vitro assay; $\mathrm{P} 2 \mathrm{X} 1$ receptor containing these point mutations also exhibited decreased currents (Bernier et al., 2008b, $2012 \mathrm{~b})$. Interestingly, it was later shown that neutralizing lysine 364 , as well as the positive arginine on position 360 also slowed the receptor recovery time after desensitization (Allsopp et al., 2013) in a mechanism that might implicate a decrease in PIP $_{n}$ binding affinity.

\section{P2X1/5}

The sensitivity of the P2X1/5 heteromeric subtype to phospholipids was studied in recombinant form via tranfection in HEK293 cells as well as in native expression in murine astrocytes acutely isolated from brain slices. In both preparations, the current carried through the $\mathrm{P} 2 \mathrm{X} 1 / 5$ channel was decreased following $\mathrm{PIP}_{\mathrm{n}}$ depletion. Under whole-cell patch-clamp configuration, the decreased channel responses could be rescued by addition of a $\mathrm{PI}(4,5) \mathrm{P}_{2}$ analog inside the recording patch pipette. The direct positive regulation by the phospholipid, combined with the noticeable insensitivity of P2X5 homomers to PIP $\mathrm{n}_{\mathrm{n}}$ levels, is indicative of a critical dominant role of the $\mathrm{P} 2 \mathrm{X} 1$ subunit in the regulation process (Ase et al., 2010). The extent to which calcium-permeable and $\mathrm{PI}(4,5) \mathrm{P}_{2}$-sensitive $\mathrm{P} 2 \mathrm{X} 1 / 5$ ATP-gated channels contribute to glial function and synaptic transmission still remains to be explored.

\section{P2X2}

The first report of $\mathrm{PIP}_{\mathrm{n}}$-dependence of a $\mathrm{P} 2 \mathrm{X}$ receptor channel came from Fujiwara and Kubo, who demonstrated that P2X2 channel gating was affected by pharmacological depletion of PIP with the PI3K blockers wortmannin and LY294002 (Fujiwara and Kubo, 2006). They observed that the relative absence of $\mathrm{PIP}_{\mathrm{n}}$ accelerated current desensitization, an effect mimicked by mutating two positively charged lysine residues of the proximal C-terminal region (K365 and K369) into neutral glutamines, indicating that an interaction between these two residues and PIP promotes the stability of the open conformation of the channel. Some P2X subtypes including P2X2 display unique activity- and time-dependent changes in channel permeability. By measuring the permeability shift in N-methyl-D-glucamine (NMDG $\left.{ }^{+}\right)$containing solutions, it was shown that this apparent pore dilation is also regulated by $\mathrm{PIP}_{\mathrm{n}}$. The direct nature of the interaction between the C-terminus of P2X2 and PIP $\mathrm{n}$ was demonstrated in two ways. By generating fusion proteins containing a region of interest from the C-terminal tail and applying them to PIP strips, it was confirmed that a direct binding can occur with several PIP ${ }_{n}$, including $3^{\prime}$ phosphorylated species dependent on PI3K activity. Using similar fusion proteins coupled to EGFP, the authors also reported association of the $\mathrm{P} 2 \mathrm{X} 2$ proximal $\mathrm{C}$-terminal tail to membrane PIP $_{\mathrm{n}}$ in COS-7 cells. Although these data lead to a primary role of $\mathrm{PI}(3) \mathrm{P}$ and $\mathrm{PI}(3,5) \mathrm{P}_{2}$, inside-out macropatch recordings performed by the Logothetis group showed that the application of $\mathrm{PI}(4,5) \mathrm{P}_{2}$ can also directly rescue the rundown of $\mathrm{P} 2 \mathrm{X} 2$ current induced by addition of polylysine, which binds and sequesters endogenous $\mathrm{PI}(4,5) \mathrm{P}_{2}$ (Zhao et al., 2007).

\section{P2X3}

As it was observed for all P2X homomers tested, the current rundown of the sensory P2X3 subtype expressed in Xenopus oocytes can be rescued by direct application of $\mathrm{PI}(4,5) \mathrm{P}_{2}$ to its intracellular domains (Zhao et al., 2007). Mo et al. (2009) then provided evidence of the $\mathrm{PI}(4,5) \mathrm{P}_{2}$-dependent regulation of the channel in native conditions, as ATP-evoked P2X3-mediated currents in 
dorsal root ganglion neurons were significantly decreased after PI4K inhibition with the furanosteroid wortmannin at micromolar concentrations (Mo et al., 2009). However, the interaction between P2X3 and PIP $_{n}$ might involve indirect modulation, as no direct binding was found between various P2X3 C-terminal regions and PIP $_{n}$ on PIP Strips. Furthermore, when expressed in heterologous systems like HEK293 cells or Xenopus oocytes, only the rate of recovery from desensitization of the receptor was affected by $\mathrm{PI}(4,5) \mathrm{P}_{2}$ levels. The absence of direct $\mathrm{PIP}_{\mathrm{n}}$ binding in vitro and the striking cell type-dependent difference in functional regulation strongly suggests that an unidentified associated protein expressed in DRG neurons provides a necessary link between P2X3 channels and phospholipids.

\section{P2X2/3}

The currents carried through the $\mathrm{P} 2 \mathrm{X} 2 / 3$ heteromer were also shown to be modulated by pharmacological PIP $_{n}$ depletion in Xenopus oocyte expression system and in native conditions in rat dorsal root ganglion neurons (Mo et al., 2009). Functionally, the $\mathrm{P} 2 \mathrm{X} 2 / 3$ receptor channel retains the $\mathrm{PIP}_{\mathrm{n}}$ sensitivity of the two subunits found in the heteromer. Blocking the formation of $3^{\prime}$ phosphorylated PIP $_{n}$ with wortmannin reduced its current amplitude, as is the case for the P2X2 homomer. On the other hand, the blockade of the PI4K-dependent synthesis of $4^{\prime}$ phosphorylated isoforms also inhibited currents, similar to what is seen for the P2X3 homomer. Moreover, following $\mathrm{PIP}_{\mathrm{n}}$ depletion, the P2X2/3 current amplitude can be partially rescued by addition of either $\mathrm{PI}(3,4,5) \mathrm{P}_{3}$ or $\mathrm{PI}(4,5) \mathrm{P}_{2}$.

\section{P2X4}

The $\mathrm{PIP}_{\mathrm{n}}$ sensitivity of the $\mathrm{P} 2 \mathrm{X} 4$ receptor channel has been extensively studied in both recombinant systems and native models. In inside-out macropatch, $\mathrm{PI}(4,5) \mathrm{P}_{2}$ increases currents carried through the P2X4 channel (Zhao et al., 2007), while whole-cell currents are inhibited by depletion of $\mathrm{PI}(3,4,5) \mathrm{P}_{3}$ or $\mathrm{PI}(4,5) \mathrm{P}_{2}$ (Bernier et al., 2008a). Subsequent intracellular injection of either of these two major signaling phospholipids leads to a recovery of the P2X4 current. Following $\mathrm{PIP}_{\mathrm{n}}$ depletion, P2X4 also exhibits a slower recovery from desensitization as well as slower activation and desensitization rates, suggesting that $\mathrm{PIP}_{\mathrm{n}}$ binding to the channel subunit triggers a conformational change that affects its gating, as was also observed with P2X1 and P2X2. P2X4-mediated ATP responses in BV2 murine microglial cells were recorded in patch clamp, and there again, $\mathrm{PIP}_{\mathrm{n}}$ act as cofactors necessary for full current amplitude. Since the P2X4 channel has the highest calcium permeability in the P2X family (Egan and Khakh, 2004), P2X4-mediated calcium entry in microglia was also assayed and a similar inhibition following $\mathrm{PIP}_{\mathrm{n}}$ depletion was observed. The capability of P2X4 to form a large conductance pore upon sustained activation was also found to be dependent on $\mathrm{PIP}_{\mathrm{n}}$ when tested in a YO-PRO-1 uptake assay in primary mouse microglia and in an assay measuring time-dependent changes in $\mathrm{NMDG}^{+}$permeability of the channel in the Xenopus oocyte heterologous expression system (Bernier et al., 2012a). Binding between a proximal region of the P2X4 C-terminal tail and various PIP $_{\mathrm{n}}$ was demonstrated using PIP strips, and individual basic residues (K362, K363, K370, K371) were found to be critical for high-affinity lipid-protein (Bernier et al., 2008a, 2012b). In functional assays, mutating two of these residues to glutamine, therefore neutralizing their positive charge and decreasing the affinity of the P2X4-PIP ${ }_{n}$ binding, induced a current that showed a slower recovery from desensitization, a slower activation rate and a slower desensitization rate. To further confirm the ability of the $\mathrm{P} 2 \mathrm{X} 4$ proximal C-terminal region (C360-V375) to bind to membrane $\mathrm{PIP}_{\mathrm{n}}$ in cellular environments, a whole-cell patch-clamp experiment was performed in P2X4expressing HEK293 cells, where fusion proteins containing the putative $\mathrm{PIP}_{\mathrm{n}}$-interacting peptide of $\mathrm{P} 2 \mathrm{X} 4$ were introduced in the patch pipette. The addition of the P2X4 C360-V375 peptide led to a decrease in the activation and desensitization rates of the $\mathrm{P} 2 \mathrm{X} 4$ channel, indicating a competition for $\mathrm{PIP}_{\mathrm{n}}$ binding between the $\mathrm{P} 2 \mathrm{X} 4$ receptor and its own $\mathrm{PIP}_{\mathrm{n}}$-binding domain. Conversely, introducing fusion proteins containing $\mathrm{PIP}_{\mathrm{n}}$ binding loss-offunction mutations abrogated the effect. Overall, these results suggest that $\mathrm{P} 2 \mathrm{X} 4$ binds directly to $\mathrm{PI}(3,4,5) \mathrm{P}_{3}$ and $\mathrm{PI}(4,5) \mathrm{P}_{2}$ via key lysine residues in the proximal C-terminal region, and that this interaction leads to conformational changes increasing the efficacy of channel activation.

\section{P2X5}

Functional data obtained in heterologous expression systems suggest that the P2X5 homomer is the only functional mammalian $\mathrm{P} 2 \mathrm{X}$ subtype insensitive to $\mathrm{PIP}_{\mathrm{n}}$ levels in the plasma membrane. A first report showed that when expressed in HEK293 cells, $\mathrm{P} 2 \mathrm{X} 5$ was unaffected by pharmacological depletion of $\mathrm{PIP}_{\mathrm{n}}$ (Ase et al., 2010). Expectedly, no direct binding between the P2X5 Cterminal tail and PIP $\mathrm{n}_{\mathrm{n}}$ could be observed using PIP strips. When various mutations were introduced on the $\mathrm{P} 2 \mathrm{X} 5 \mathrm{C}$-terminus to improve its binding affinity to $\operatorname{PIP}_{\mathrm{n}}$, the current carried by the P2X5 channel was greatly increased, and the mutated receptor acquired sensitivity to wortmannin-induced $\mathrm{PIP}_{\mathrm{n}}$ depletion, implying that the relatively small currents obtained in WT P2X5 were due to a lack of PIP $_{n}$-dependent potentiation (Bernier et al., 2012b). Furthermore, the PIP $_{n}$-binding mutant P2X5 exhibited a faster recovery from desensitization, as well as faster activation and desensitization rates, whereas pharmacological PIP $_{n}$ depletion led to a current phenotype similar to that observed with wildtype P2X5. The profound changes seen in the gating properties of the $\mathrm{PIP}_{\mathrm{n}}$-binding $\mathrm{P} 2 \mathrm{X} 5$ mutant further confirms the important functional role phospholipids play on $\mathrm{P} 2 \mathrm{X}$ function.

\section{P2X7}

The initial observation of $\mathrm{PIP}_{\mathrm{n}}$-dependence of the $\mathrm{P} 2 \mathrm{X} 7$ receptor came from the Logothetis group, who demonstrated that pharmacological inhibition of $\mathrm{PI}(4,5) \mathrm{P}_{2}$ synthesis reduced the P2X7 current density in Xenopus oocytes and HEK293 cells (Zhao et al., 2007). PLC-dependent $\mathrm{PI}(4,5) \mathrm{P}_{2}$ hydrolysis induced by platelet-derived growth factor receptor (PDGFR) activation was also shown to partially inhibit P2X7 function and addition of $\mathrm{PI}(4,5) \mathrm{P}_{2}$ directly reversed the rundown of $\mathrm{P} 2 \mathrm{X} 7$ current in inside-out macropatches. Furthermore, three positively-charged amino acid residues of the $\mathrm{C}$-terminal domain were found to be critical in the $\mathrm{PI}(4,5) \mathrm{P}_{2}$-dependence of the $\mathrm{P} 2 \mathrm{X} 7$ receptor. However, no direct binding was observed between the P2X7 
C-terminal tail and $\mathrm{PIP}_{\mathrm{n}}$ on PIP strip membranes, suggesting that the channel-lipid interactions might be indirect (Bernier et al., 2012b).

\section{MOLECULAR DETERMINANTS OF THE PIP ${ }_{\mathrm{n}}$ INTERACTION WITH P2X RECEPTORS}

As all ATP-activated P2X subtypes except P2X5 were shown to be functionally regulated by $\mathrm{PIP}_{n}$, it is critical to characterize the nature of the protein-lipid interaction. For all $\mathrm{PIP}_{\mathrm{n}}$-sensitive subtypes, several basic amino acid residues were shown through mutational assays to be necessary for the regulation. This is in accordance with most $\mathrm{PIP}_{\mathrm{n}}$-binding regions of other types of proteins; while no consensus sequence exists for $\mathrm{PIP}_{\mathrm{n}}$ binding, the presence of positively-charged residues, often found in clusters, is necessary for an electrostatic interaction to take place with the negatively-charged head of the lipid (Rosenhouse-Dantsker and Logothetis, 2007; Whorton and Mackinnon, 2011). For P2X receptors, it is hypothesized that an intracellular domain containing a dual cluster of basic amino acids, mainly arginines and lysines located on the C-terminal tail 6 to 19 residues away from the second transmembrane domain, is required for $\mathrm{PIP}_{\mathrm{n}}$ binding (Bernier et al., 2012b). Some subtypes, including P2X3, P2X7 and the $\mathrm{PIP}_{\mathrm{n}}$-insensitive $\mathrm{P} 2 \mathrm{X} 5$ lack this characteristic domain and hence do not directly bind to PIP $_{n}$. Analysis of the basic and hydrophobic $(\mathrm{BH})$ score of $\mathrm{P} 2 \mathrm{X}$ C-terminal regions, using a quantification method that measures the lipid binding affinity of unstructured linear protein sequences (Brzeska et al., 2010), also predicts the presence of a lipid binding site on most P2X subunits (Figure 1). The high $\mathrm{BH}$ score region corresponds to the dual polybasic cluster motif experimentally confirmed (Bernier et al., 2012b). Furthermore, mutational analysis of P2X5 indicated that the regulatory dual cluster motif is not only necessary, but also sufficient for $\mathrm{PIP}_{\mathrm{n}}$-dependent regulation, as creation of the putative $\mathrm{PIP}_{\mathrm{n}}$ binding site via neutral- or acidic-to-basic mutation induced a current phenotype functionally modulated by $\mathrm{PIP}_{\mathrm{n}}$. Similar regulatory $\mathrm{PIP}_{\mathrm{n}}$-binding motifs have been found on multiple PIP $_{n}$-dependent channels, including members of the TRPM family which bind to PIP $_{\mathrm{n}}$ via the TRP box, and M-type potassium channels $(\mathrm{Kv} 7)$ interacting with $\mathrm{PIP}_{\mathrm{n}}$ via a polybasic cluster (Rohacs et al., 2005; Nilius et al., 2008; Hernandez et al., 2008a; Hansen et al., 2011).

Whereas direct binding between phospholipids and the binding motif in vitro correctly predicts sensitivity to $\mathrm{PIP}_{\mathrm{n}}$ and phenotype for most P2X subtypes, results obtained with $\mathrm{P} 2 \mathrm{X} 3$ and $\mathrm{P} 2 \mathrm{X} 7$ indicate that indirect $\mathrm{PIP}_{\mathrm{n}}$ modulation can also influence channel properties. Several acidic residues are found within the $\mathrm{PIP}_{\mathrm{n}}$ binding site of $\mathrm{P} 2 \mathrm{X} 3$, disrupting the global positive charge of the clusters and reducing its binding affinity. On the other hand, the P2X7 sequence displays only one polybasic cluster. Accordingly, no direct binding to PIP $_{n}$ was observed for the two subtypes (Mo et al., 2009; Bernier et al., 2012b). However, functional regulation of the $\mathrm{P} 2 \mathrm{X} 3$ and $\mathrm{P} 2 \mathrm{X} 7$ channels by $\mathrm{PIP}_{\mathrm{n}}$ was observed in various models, leading to the hypothesis of an association with a cofactor acting as an indirect sensor of $\mathrm{PIP}_{\mathrm{n}}$ levels in the plasma membrane (Zhao et al., 2007; Mo et al., 2009). Indirect interactions have been demonstrated for various $\mathrm{PIP}_{\mathrm{n}}$-sensitive channels: the potentiation of TRPV1 by $\mathrm{PIP}_{\mathrm{n}}$ relies

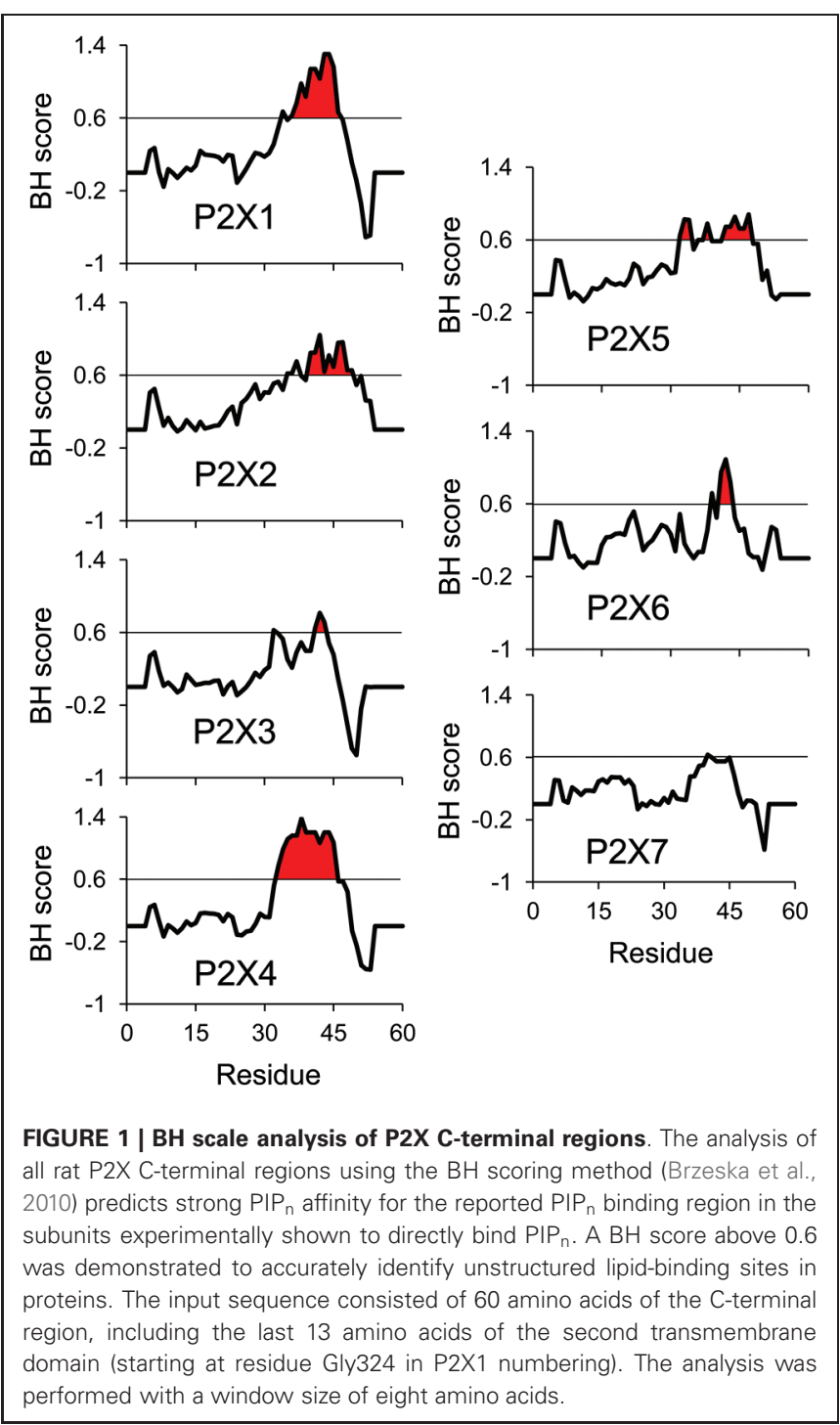

on phosphoinositide interacting regulator of TRP (PIRT) acting as a linker between both molecules, and N-methyl-D-aspartate (NMDA) glutamate receptors are regulated by $\mathrm{PIP}_{\mathrm{n}}$ via $\alpha$-actinin interacting with both the lipids and the NR1 and NR2b subunits to promote channel opening (Michailidis et al., 2007; Kim et al., 2008). Interestingly, the long P2X7 C-terminal domain directly associates with various proteins including $\alpha$-actinin, possibly linking the channel subunit to PIP $_{n}$ (Kim et al., 2001).

The exact molecular mechanism by which protein-PIP $\mathrm{P}_{\mathrm{n}}$ binding induces changes in the functional phenotype of $\mathrm{P} 2 \mathrm{X}$ channels remains elusive. However, it is likely that such interaction, whether it be direct or indirect, triggers a conformational change in TM2 linked to the proximal C-terminal domain. Recent evidence from crystallization of the $\mathrm{PIP}_{n}$-binding and $\mathrm{PIP}_{n}$-sensitive Kir2.2 channel in the presence of $\mathrm{PIP}_{2}$ demonstrates that a similar channel-lipid interaction can lead to significant movements of the cytosolic domains, by as much as $6 \AA$ (Haider et al., 2007; Hansen et al., 2011; Whorton and Mackinnon, 2011). The recent crystallographic data of P2X4 unfortunately do not contain the cytosolic C-terminal domain where the P2X PIP $\mathrm{P}_{\mathrm{n}}$ binding site is 


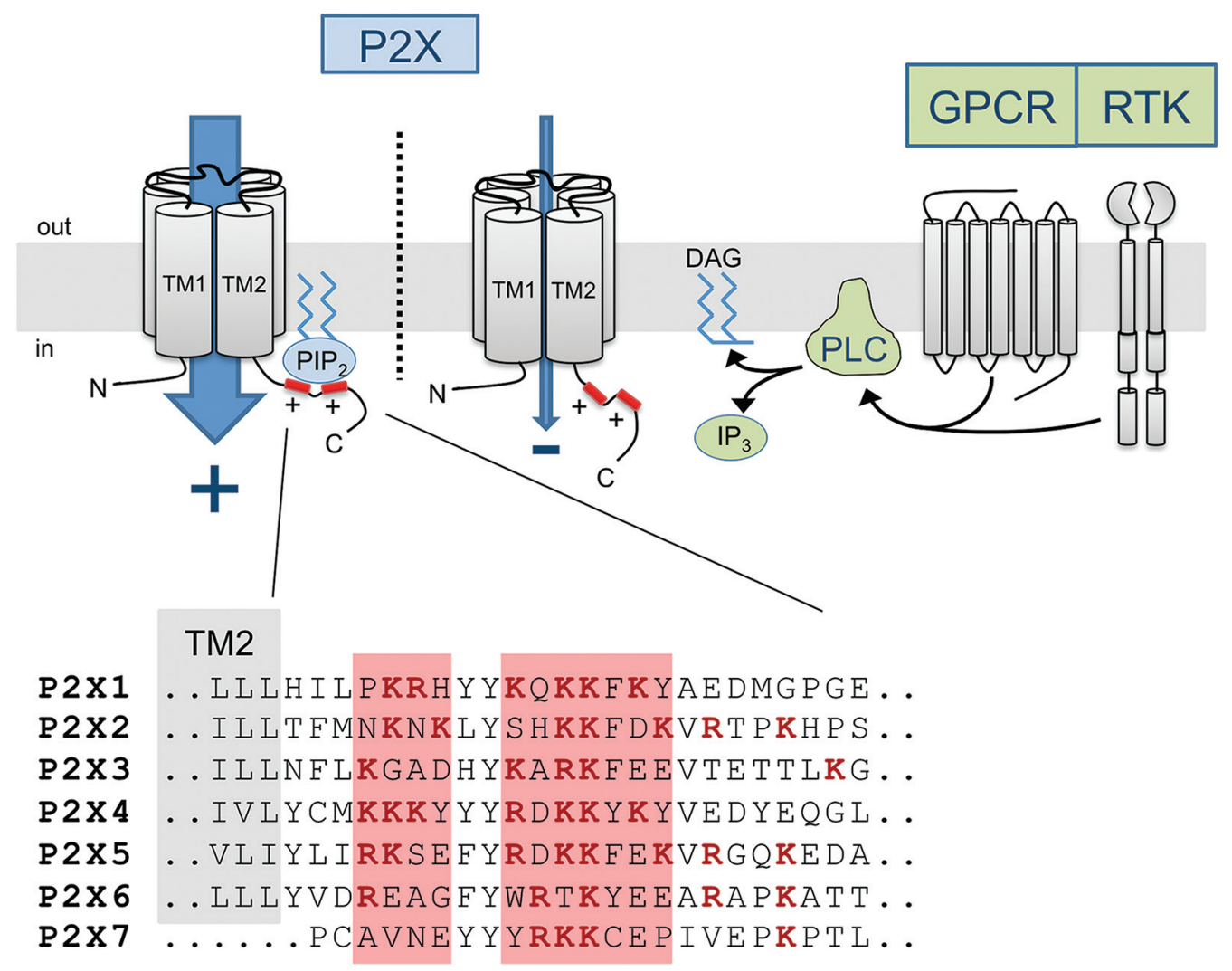

FIGURE 2 | Diagram of the PIP $_{n}$-dependent metabotropic regulation of P2X receptor channels. Membrane-bound $\mathrm{PIP}_{\mathrm{n}}$ directly bind a dual polybasic cluster motif found in the $\mathrm{C}$-terminal region of certain $\mathrm{P} 2 \mathrm{X}$ receptor subtypes, modulating the current carried through the channel. $G$ proteincoupled receptor (GPCR) or receptor tyrosine kinase (RTK) activation induces
PLC-mediated hydrolysis of $\mathrm{PI}(4,5) \mathrm{P}_{2}$, transiently reducing the levels of $\mathrm{PI}(4,5) \mathrm{P}_{2}$ and affecting $\mathrm{P} 2 \mathrm{X}$ function. The amino acid sequence of the proximal $\mathrm{C}$-terminal regions of $\mathrm{P} 2 \mathrm{X}$ receptors shows the presence of two clusters of basic residues forming a regulatory $\mathrm{PIP}_{\mathrm{n}}$ binding site in most subunits. located (Kawate et al., 2009; Hattori and Gouaux, 2012). Interestingly, the regulatory $\mathrm{PIP}_{\mathrm{n}}$ binding site, being in close proximity to the second transmembrane domain, is located only 15 to 20 amino acids away from the gate region of the pore controlling the ion conduction properties of the channel (Figure 2). Since conformational changes in the gate area upon ATP binding mediate the opening of the channel as well as its desensitization (Kracun et al., 2010; Li et al., 2010; Kawate et al., 2011; Du et al., 2012; Hattori and Gouaux, 2012), it is likely that forces generated by lipid binding affect the movements of the region and alter the gating kinetics of the channel, as PIP $_{n}$ level-dependent changes in channel activation and desensitization rates have been observed in most P2X subtypes.

Furthermore, the ability of $\mathrm{P} 2 \mathrm{X} 2$ and $\mathrm{P} 2 \mathrm{X} 4$ receptor channels to dilate into a large conductance pore is also sensitive to PIP $_{n}$ levels (Fujiwara and Kubo, 2006; Bernier et al., 2012a). This activity-dependent change in permeability is believed to be driven in part by major rearrangements in the interactions between the transmembrane domains (Eickhorst et al., 2002; Chaumont and Khakh, 2008; Shinozaki et al., 2009). For P2X2, 10 residues in the transmembrane domains were shown to be involved in the transition to the high permeability state, several of which are in close proximity to the $\mathrm{PIP}_{\mathrm{n}}$ binding site (Fisher et al., 2004; Khakh and Egan, 2005). Also arguing for a role of $\mathrm{PIP}_{\mathrm{n}}$ in regulating the large pore formation via conformational changes are reports demonstrating that the change in permeability requires rearrangements of the cytosolic domains where the channel-lipid interaction site is found. More specifically, a study using a chimeric $\mathrm{P} 2 \mathrm{X} 2$ engineered with a $\mathrm{PIP}_{2}$-binding pleckstrin homology $(\mathrm{PH})$ domain fused to its $\mathrm{C}$-terminal tail showed that $\mathrm{PIP}_{2}$ can tether the domain to the membrane, thereby preventing the transition of P2X2 into a dilated state (Fisher et al., 2004).

While we can speculate that $\operatorname{PIP}_{n}$ binding induces a rearrangement of the C-terminal tail of $\mathrm{P} 2 \mathrm{X}$ channels and in this way changes its functional properties, it remains unclear how specific the interaction is with regards to the various $\mathrm{PIP}_{n}$ species present in cellular environments. P2X1, P2X3 and P2X7 seem to be strongly potentiated by $\mathrm{PI}(4,5) \mathrm{P}_{2}, \mathrm{P} 2 \mathrm{X} 2$ is mainly modulated by the $3^{\prime}$ phosphorylated $\mathrm{PIP}_{\mathrm{n}}\left[\mathrm{PI} 3 \mathrm{P}, \mathrm{PI}(3,5) \mathrm{P}_{2}\right]$, while $\mathrm{P} 2 \mathrm{X} 4$ depends on both $\mathrm{PIP}(4,5) \mathrm{P}_{2}$ and $\mathrm{PI}(3,4,5) \mathrm{P}_{3}$ as cofactors for full activation. Parallels will be drawn between $\mathrm{P} 2 \mathrm{X}$ receptors and other families of PIP $_{n}$-dependent ion channels in terms of protein-lipid binding characteristics. Most phospholipiddependent channels and transporters require $\mathrm{PI}(4,5) \mathrm{P}_{2}$ however some are modulated by $\mathrm{PI} 3 \mathrm{P}$ and $\mathrm{PI}(3,5) \mathrm{P}_{2}$, like smallconductance $\mathrm{Ca}^{2+}$-activated $\mathrm{K}^{+}$channels, or by $\mathrm{PI}(3,4,5) \mathrm{P}_{3}$, like 
CNG channels and epithelial sodium channels (Zhainazarov et al., 2004; Pochynyuk et al., 2005; Srivastava et al., 2006). For P2X receptor channels, while subtype-specific variations in the primary sequence of the regulatory PIP $_{n}$ site could provide some binding specificity to $\mathrm{PIP}_{n}$ species, it is likely that the regulation is mostly directed by the relative abundance of specific PIP $_{n}$ in the membrane microenvironment surrounding the channel. Unlike $\mathrm{PH}$ domains which require a complex protein folding and basic residues scattered over a region of hundreds of amino acids, the shorter and more linear P2X PIP $\mathrm{n}$ binding site only forms a cluster of positive charges electrostatically interacting with the negative head group of the lipid, providing a lower level of specificity.

\section{A PHYSIOLOGICAL ROLE FOR PIP ${ }_{\mathrm{n}}$ REGULATION OF P2X}

Intracellular $\mathrm{PIP}_{\mathrm{n}}$ levels can fluctuate very rapidly within the plasma membrane. Many surface receptors are coupled to the activation of PLC isoforms, transiently lowering the levels of $\mathrm{PI}(4,5) \mathrm{P}_{2}$ via hydrolysis, while enzymes involved in $\mathrm{PIP}_{n}$ synthesis, like PI3K or the phosphatase and tensin homolog (PTEN), are tightly regulated via multiple signaling cascades. Therefore, receptor channels requiring the presence of $\mathrm{PIP}_{\mathrm{n}}$ as essential cofactor for complete function can be regulated by enzyme-driven depletion or addition of PIP ${ }_{n}$ species. Multiple examples of PIP $_{n^{-}}$ dependent ion channel regulation through metabotropic pathways exist, including M1 muscarinic receptor-mediated inhibition of KCNQ channels, Trk- and PLC-mediated inhibition of TRPM7 or $G$ protein-coupled inwardly-rectifying potassium (GIRK) channels (Caulfield et al., 1994; Kobrinsky et al., 2000; Runnels et al., 2002; Cho et al., 2005; Brown et al., 2007; Falkenburger et al., 2010). The first report of $\mathrm{P} 2 \mathrm{X}$ receptor channels being regulated through receptor-initiated depletion of $\mathrm{PI}(4,5) \mathrm{P}_{2}$ came from the Logothetis group, who showed that P2X7 currents are inhibited by co-activation of PDGFR in Xenopus oocytes (Zhao et al., 2007). The inhibition specifically depends on $\mathrm{PIP}_{2}$ hydrolysis as it does not occur following activation of a PLC $\gamma$-deficient mutant PDGFR. Another multireceptor crosstalk involving PIP was later reported natively as cationic currents carried through the $\mathrm{P} 2 \mathrm{X} 3$ receptors in isolated dorsal root ganglion neurons are reduced after activation of the UTP-sensitive P2Y2 $G_{q}$ proteincoupled receptor (Mo et al., 2013). This interaction can be occluded by exogenous introduction of a $\mathrm{PIP}_{2}$ analog as well as by pharmacologically uncoupling the P2Y2 receptor from PLC activation, indicating that $\mathrm{P} 2 \mathrm{X} 3$ inhibition by $\mathrm{P} 2 \mathrm{Y} 2$ directly relies on $\mathrm{PI}(4,5) \mathrm{P}_{2}$ hydrolysis. A third crosstalk was recently uncovered in microglia, where $\mathrm{P} 2 \mathrm{X} 4$ receptor channels are functionally inhibited by co-activation of the $\mathrm{G}_{q}$-coupled P2Y6 receptor also upregulated in neuropathic pain conditions (Bernier et al., 2013). UDP activation of P2Y6 leads to a PLC-dependent decrease in P2X4-mediated currents and calcium entry in both resting and LPS-activated microglia. The dilation of P2X4 into a large conductance pore was also inhibited by P2Y6 activation, all of these effects being highly similar to that of pharmacological depletion of PIP .

These recent results suggest that the requirement of $\mathrm{PIP}_{n}$ as a cofactor for $\mathrm{P} 2 \mathrm{X}$ receptor is a critical regulatory mechanism involved in signaling crosstalks under physiological and pathological conditions. Many aspects of this post-translational modulatory mechanism remain to be investigated to understand its physiological significance. For example, it is still unclear if and how this modulatory pathway can be specific to one metabotropic receptor. Can $\mathrm{P} 2 \mathrm{X}$ receptors be inhibited by any signaling event inducing PLC hydrolysis of $\mathrm{PI}(4,5) \mathrm{P}_{2}$ ? Interestingly, stimulating $\mathrm{G}_{q}$-coupled P2Y1 ADP receptors or M3 muscarinic receptors failed to inhibit P2X4 responses in transfected HEK293 cells while stimulating P2Y6 receptors did, indicating some degree of specificity to the P2Y6-P2X4 crosstalk (Bernier et al., 2013). It is probable that subcellular localization plays a key role in controlling which receptors interact. $\mathrm{PI}(4,5) \mathrm{P}_{2}$ hydrolysis by PLC likely induces only a local depletion in $\mathrm{PI}(4,5) \mathrm{P}_{2}$ levels and could therefore preferentially affect adjacent P2X receptors. It would be interesting to investigate the role of lipid rafts in controlling the proximity of different receptors, considering that plasma membrane microenvironments have been reported to affect P2X physiology (Vacca et al., 2004; Vial and Evans, 2005; Allsopp et al., 2010). Other factors such as GPCR desensitization might also come into play given that $\mathrm{PIP}_{\mathrm{n}}$ levels have a fast turnover rate. For example, P2Y6 displays a much slower desensitization pattern than other P2Y receptors and might induce a longer, more significant decrease in membrane $\mathrm{PI}(4,5) \mathrm{P}_{2}$ level (Robaye et al., 1997).

As an increasing amount of data highlights the role of $\mathrm{PIP}_{n}$ in $\mathrm{P} 2 \mathrm{X}$ receptor activity and multireceptor crosstalks, such a posttranslational regulatory mechanism might provide an innovative pharmacological target to treat chronic pain conditions or immune diseases where $\mathrm{P} 2 \mathrm{X}$ receptors are known to be involved.

\section{REFERENCES}

Allsopp, R. C., Farmer, L. K., Fryatt, A. G., and Evans, R. J. (2013). P2X Receptor chimeras highlight roles of the amino terminus to partial agonist efficacy, the carboxyl terminus to recovery from desensitization, and independent regulation of channel transitions. J. Biol. Chem. 288, 21412-21421. doi: 10.1074/jbc.m113. 464651

Allsopp, R. C., Lalo, U., and Evans, R. J. (2010). Lipid raft association and cholesterol sensitivity of P2X1-4 receptors for ATP: chimeras and point mutants identify intracellular amino-terminal residues involved in lipid regulation of P2X1 receptors. J. Biol. Chem. 285, 32770-32777. doi: 10.1074/jbc.m110.148940

Ase, A. R., Bernier, L. P., Blais, D., Pankratov, Y., and Seguela, P. (2010). Modulation of heteromeric $\mathrm{P} 2 \mathrm{X} 1 / 5$ receptors by phosphoinositides in astrocytes depends on the P2X1 subunit. J. Neurochem. 113, 1676-1684. doi: 10.1111/j.1471-4159. 2010.06734.x

Bernier, L. P., Ase, A. R., Boue-Grabot, E., and Seguela, P. (2012a). P2X4 receptor channels form large noncytolytic pores in resting and activated microglia. Glia 60, 728-737. doi: 10.1002/glia.22301

Bernier, L. P., Ase, A. R., Boué-Grabot, É., and Séguéla, P. (2013). Inhibition of P2X4 function by P2Y6 UDP receptors in microglia. Glia 61, 2038-2049. doi: 10.1002/ glia.22574

Bernier, L. P., Ase, A. R., Chevallier, S., Blais, D., Zhao, Q., Boue-Grabot, E., et al. (2008a). Phosphoinositides regulate P2X4 ATP-gated channels through direct interactions. J. Neurosci. 28, 12938-12945. doi: 10.1523/jneurosci.3038-08.2008

Bernier, L. P., Ase, A. R., Tong, X., Hamel, E., Blais, D., Zhao, Q., et al. (2008b). Direct modulation of $\mathrm{P} 2 \mathrm{X} 1$ receptor-channels by the lipid phosphatidylinositol 4,5-bisphosphate. Mol. Pharmacol. 74, 785-792. doi: 10.1124/mol.108.047019

Bernier, L. P., Blais, D., Boue-Grabot, E., and Seguela, P. (2012b). A dual polybasic motif determines phosphoinositide binding and regulation in the P2X channel family. PLoS One 7:e40595. doi: 10.1371/journal.pone.0040595

Berridge, M. J. (1993). Inositol trisphosphate and calcium signalling. Nature 361, 315-325. doi: 10.1038/361315a0

Brown, D. A., Hughes, S. A., Marsh, S. J., and Tinker, A. (2007). Regulation of $\mathrm{M}(\mathrm{Kv} 7.2 / 7.3)$ channels in neurons by $\mathrm{PIP}(2)$ and products of PIP(2) hydrolysis: significance for receptor-mediated inhibition. J. Physiol. 582, 917-925. doi: 10. 1113/jphysiol.2007.132498 
Brzeska, H., Guag, J., Remmert, K., Chacko, S., and Korn, E. D. (2010). An experimentally based computer search identifies unstructured membrane-binding sites in proteins: application to class I myosins, PAKS, and CARMIL. J. Biol. Chem. 285, 5738-5747. doi: 10.1074/jbc.m109.066910

Caulfield, M. P., Jones, S., Vallis, Y., Buckley, N. J., Kim, G. D., Milligan, G., et al. (1994). Muscarinic M-current inhibition via G alpha $q / 11$ and alphaadrenoceptor inhibition of $\mathrm{Ca} 2+$ current via $\mathrm{G}$ alpha $\mathrm{o}$ in rat sympathetic neurones. J. Physiol. 477, 415-422.

Chaumont, S., and Khakh, B. S. (2008). Patch-clamp coordinated spectroscopy shows P2X2 receptor permeability dynamics require cytosolic domain rearrangements but not Panx-1 channels. Proc. Natl. Acad. Sci. U S A 105, $12063-$ 12068. doi: 10.1073/pnas.0803008105

Cho, H., Lee, D., Lee, S. H., and Ho, W. K. (2005). Receptor-induced depletion of phosphatidylinositol 4,5-bisphosphate inhibits inwardly rectifying $\mathrm{K}+$ channels in a receptor-specific manner. Proc. Natl. Acad. Sci. U S A 102, 4643-4648. doi: 10.1073/pnas.0408844102

Coddou, C., Yan, Z., Obsil, T., Huidobro-Toro, J. P., and Stojilkovic, S. S. (2011). Activation and regulation of purinergic P2X receptor channels. Pharmacol. Rev. 63, 641-683. doi: 10.1124/pr.110.003129

Doughman, R. L., Firestone, A. J., and Anderson, R. A. (2003). Phosphatidylinositol phosphate kinases put PI4,5P(2) in its place. J. Membr. Biol. 194, 77-89. doi: 10. 1007/s00232-003-2027-7

Du, J., Dong, H., and Zhou, H. X. (2012). Gating mechanism of a P2X4 receptor developed from normal mode analysis and molecular dynamics simulations. Proc. Natl. Acad. Sci. U S A 109, 4140-4145. doi: 10.1073/pnas.1119546109

Egan, T. M., and Khakh, B. S. (2004). Contribution of calcium ions to P2X channel responses. J. Neurosci. 24, 3413-3420. doi: 10.1523/jneurosci.5429-03.2004

Eickhorst, A. N., Berson, A., Cockayne, D., Lester, H. A., and Khakh, B. S. (2002). Control of P2X(2) channel permeability by the cytosolic domain. J. Gen. Physiol. 120, 119-131. doi: 10.1085/jgp.20028535

Falkenburger, B. H., Jensen, J. B., Dickson, E. J., Suh, B. C., and Hille, B. (2010). Phosphoinositides: lipid regulators of membrane proteins. J. Physiol. 588, 31793185. doi: 10.1113/jphysiol.2010.192153

Fisher, J. A., Girdler, G., and Khakh, B. S. (2004). Time-resolved measurement of state-specific P2X2 ion channel cytosolic gating motions. J. Neurosci. 24, 1047510487. doi: 10.1523/jneurosci.3250-04.2004

Fujiwara, Y., and Kubo, Y. (2006). Regulation of the desensitization and ion selectivity of ATP-gated P2X2 channels by phosphoinositides. J. Physiol. 576, 135-149. doi: 10.1113/jphysiol.2006.115246

Gamper, N., and Shapiro, M. S. (2007). Regulation of ion transport proteins by membrane phosphoinositides. Nat. Rev. Neurosci. 8, 921-934. doi: 10. $1038 /$ nrn 2257

Haider, S., Tarasov, A. I., Craig, T. J., Sansom, M. S., and Ashcroft, F. M. (2007). Identification of the PIP2-binding site on Kir6.2 by molecular modelling and functional analysis. EMBO J. 26, 3749-3759. doi: 10.1038/sj.emboj.7601809

Hansen, S. B., Tao, X., and Mackinnon, R. (2011). Structural basis of PIP2 activation of the classical inward rectifier K+ channel Kir2.2. Nature 477, 495498. doi: 10.1038/nature 10370

Hattori, M., and Gouaux, E. (2012). Molecular mechanism of ATP binding and ion channel activation in P2X receptors. Nature 485, 207-212. doi: 10. 1038/nature11010

Heo, W. D., Inoue, T., Park, W. S., Kim, M. L., Park, B. O., Wandless, T. J., et al. (2006). $\mathrm{PI}(3,4,5) \mathrm{P} 3$ and $\mathrm{PI}(4,5) \mathrm{P} 2$ lipids target proteins with polybasic clusters to the plasma membrane. Science 314, 1458-1461. doi: 10.1126/science. 1134389

Hernandez, C. C., Zaika, O., and Shapiro, M. S. (2008a). A carboxy-terminal inter-helix linker as the site of phosphatidylinositol 4,5-bisphosphate action on Kv7 (M-type) K+ channels. J. Gen. Physiol. 132, 361-381. doi: 10.1085/jgp. 200810007

Hernandez, C. C., Zaika, O., Tolstykh, G. P., and Shapiro, M. S. (2008b). Regulation of neural KCNQ channels: signalling pathways, structural motifs and functional implications. J. Physiol. 586, 1811-1821. doi: 10.1113/jphysiol.2007. 148304

Huang, C. L., Feng, S., and Hilgemann, D. W. (1998). Direct activation of inward rectifier potassium channels by PIP2 and its stabilization by Gbetagamma. Nature 391, 803-806. doi: 10.1038/35882

Kawate, T., Michel, J. C., Birdsong, W. T., and Gouaux, E. (2009). Crystal structure of the ATP-gated P2X(4) ion channel in the closed state. Nature 460, 592-598. doi: $10.1038 /$ nature 08198
Kawate, T., Robertson, J. L., Li, M., Silberberg, S. D., and Swartz, K. J. (2011). Ion access pathway to the transmembrane pore in $\mathrm{P} 2 \mathrm{X}$ receptor channels. J. Gen. Physiol. 137, 579-590. doi: 10.1085/jgp.201010593

Khakh, B. S., and Egan, T. M. (2005). Contribution of transmembrane regions to ATP-gated P2X2 channel permeability dynamics. J. Biol. Chem. 280, 6118-6129. doi: 10.1074/jbc.m411324200

Kim, A. Y., Tang, Z., Liu, Q., Patel, K. N., Maag, D., Geng, Y., et al. (2008). Pirt, a phosphoinositide-binding protein, functions as a regulatory subunit of TRPV1. Cell 133, 475-485. doi: 10.1016/j.cell.2008.02.053

Kim, M., Jiang, L. H., Wilson, H. L., North, R. A., and Surprenant, A. (2001). Proteomic and functional evidence for a $\mathrm{P} 2 \mathrm{X} 7$ receptor signalling complex. EMBO J. 20, 6347-6358. doi: 10.1093/emboj/20.22.6347

Kobrinsky, E., Mirshahi, T., Zhang, H., Jin, T., and Logothetis, D. E. (2000). Receptor-mediated hydrolysis of plasma membrane messenger PIP2 leads to K+-current desensitization. Nat. Cell Biol. 2, 507-514. doi: 10. $1038 / 35019544$

Korzeniowski, M. K., Popovic, M. A., Szentpetery, Z., Varnai, P., Stojilkovic, S. S., and Balla, T. (2009). Dependence of STIM1/Orail-mediated calcium entry on plasma membrane phosphoinositides. J. Biol. Chem. 284, 21027-21035. doi: 10. 1074/jbc.m109.012252

Kracun, S., Chaptal, V., Abramson, J., and Khakh, B. S. (2010). Gated access to the pore of a P2X receptor: structural implications for closed-open transitions. J. Biol. Chem. 285, 10110-10121. doi: 10.1074/jbc.m109.089185

Kunzelmann, K., Bachhuber, T., Regeer, R., Markovich, D., Sun, J., and Schreiber, R. (2005). Purinergic inhibition of the epithelial $\mathrm{Na}+$ transport via hydrolysis of PIP2. FASEB J. 19, 142-143. doi: 10.1096/fj.04-2314fje

Li, M., Kawate, T., Silberberg, S. D., and Swartz, K. J. (2010). Pore-opening mechanism in trimeric P2X receptor channels. Nat. Commun. 1:44. doi: 10.1038/ ncomms 1048

Logothetis, D. E., Jin, T., Lupyan, D., and Rosenhouse-Dantsker, A. (2007). Phosphoinositide-mediated gating of inwardly rectifying $\mathrm{K}(+)$ channels. Pflugers Arch. 455, 83-95. doi: 10.1007/s00424-007-0276-5

Logothetis, D. E., Petrou, V. I., Adney, S. K., and Mahajan, R. (2010). Channelopathies linked to plasma membrane phosphoinositides. Pflugers Arch. 460, 321-341. doi: 10.1007/s00424-010-0828-y

Michailidis, I. E., Helton, T. D., Petrou, V. I., Mirshahi, T., Ehlers, M. D., and Logothetis, D. E. (2007). Phosphatidylinositol-4,5-bisphosphate regulates NMDA receptor activity through alpha-actinin. J. Neurosci. 27, 5523-5532. doi: 10.1523/jneurosci.4378-06.2007

Mo, G., Bernier, L. P., Zhao, Q., Chabot-Dore, A. J., Ase, A. R., Logothetis, D., et al. (2009). Subtype-specific regulation of $\mathrm{P} 2 \mathrm{X} 3$ and $\mathrm{P} 2 \mathrm{X} 2 / 3$ receptors by phosphoinositides in peripheral nociceptors. Mol. Pain 5:47. doi: 10.1186/17448069-5-47

Mo, G., Peleshok, J. C., Cao, C. Q., Ribeiro-Da-Silva, A., and Seguela, P. (2013). Control of P2X3 channel function by metabotropic P2Y2 utp receptors in primary sensory neurons. Mol. Pharmacol. 83, 640-647. doi: 10.1124/mol.112. 082099

Monserrate, J. P., and York, J. D. (2010). Inositol phosphate synthesis and the nuclear processes they affect. Curr. Opin. Cell Biol. 22, 365-373. doi: 10.1016/j. ceb.2010.03.006

Nilius, B., Owsianik, G., and Voets, T. (2008). Transient receptor potential channels meet phosphoinositides. EMBO J. 27, 2809-2816. doi: 10.1038/emboj.2008.217

North, R. A. (2002). Molecular physiology of P2X receptors. Physiol. Rev. 82, 1013 1067. doi: 10.1152/physrev.00015.2002

Pochynyuk, O., Staruschenko, A., Tong, Q., Medina, J., and Stockand, J. D. (2005). Identification of a functional phosphatidylinositol 3,4,5-trisphosphate binding site in the epithelial Na+ channel. J. Biol. Chem. 280, 37565-37571. doi: 10. 1074/jbc.m509071200

Prestwich, G. D. (2004). Phosphoinositide signaling; from affinity probes to pharmaceutical targets. Chem. Biol. 11, 619-637. doi: 10.1016/j.chembiol.2004.03. 025

Robaye, B., Boeynaems, J. M., and Communi, D. (1997). Slow desensitization of the human P2Y6 receptor. Eur. J. Pharmacol. 329, 231-236. doi: 10.1016/s00142999(97)10123-6

Rohacs, T. (2007). Regulation of TRP channels by PIP(2). Pflugers Arch. 453, 753762. doi: 10.1007/s00424-006-0153-7

Rohacs, T., Lopes, C. M., Michailidis, I., and Logothetis, D. E. (2005). PI(4,5)P2 regulates the activation and desensitization of TRPM8 channels through the TRP domain. Nat. Neurosci. 8, 626-634. doi: 10.1038/nn1451 
Rosenhouse-Dantsker, A., and Logothetis, D. E. (2007). Molecular characteristics of phosphoinositide binding. Pflugers Arch. 455, 45-53. doi: 10.1007/s00424-0070291-6

Runnels, L. W., Yue, L., and Clapham, D. E. (2002). The TRPM7 channel is inactivated by PIP(2) hydrolysis. Nat. Cell Biol. 4, 329-336. doi: 10.1038/ncb781

Shinozaki, Y., Sumitomo, K., Tsuda, M., Koizumi, S., Inoue, K., and Torimitsu, K. (2009). Direct observation of ATP-induced conformational changes in single P2X4 receptors. PLoS Biol. 7:e1000103. doi: 10.1371/journal.pbio.1000103

Srivastava, S., Choudhury, P., Li, Z., Liu, G., Nadkarni, V., Ko, K., et al. (2006). Phosphatidylinositol 3-phosphate indirectly activates KCa3.1 via 14 amino acids in the carboxy terminus of KCa3.1. Mol. Biol. Cell 17, 146-154. doi: 10. 1091/mbc.e05-08-0763

Suh, B. C., and Hille, B. (2005). Regulation of ion channels by phosphatidylinositol 4,5-bisphosphate. Curr. Opin. Neurobiol. 15, 370-378. doi: 10.1016/j.conb.2005. 05.005

Toker, A. (1998). The synthesis and cellular roles of phosphatidylinositol 4,5-bisphosphate. Curr. Opin. Cell Biol. 10, 254-261. doi: 10.1016/s09550674(98)80148-8

Vacca, F., Amadio, S., Sancesario, G., Bernardi, G., and Volonte, C. (2004). P2X3 receptor localizes into lipid rafts in neuronal cells. J. Neurosci. Res. 76, 653-661. doi: 10.1002/jnr.20069

Vial, C., and Evans, R. J. (2005). Disruption of lipid rafts inhibits P2X1 receptormediated currents and arterial vasoconstriction. J. Biol. Chem. 280, 3070530711. doi: 10.1074/jbc.m504256200

Whorton, M. R., and Mackinnon, R. (2011). Crystal structure of the mammalian GIRK2 $\mathrm{K}+$ channel and gating regulation by $\mathrm{G}$ proteins, PIP2, and sodium. Cell 147, 199-208. doi: 10.1016/j.cell.2011.07.046
Womack, K. B., Gordon, S. E., He, F., Wensel, T. G., Lu, C. C., and Hilgemann, D. W. (2000). Do phosphatidylinositides modulate vertebrate phototransduction? J. Neurosci. 20, 2792-2799.

Zhainazarov, A. B., Spehr, M., Wetzel, C. H., Hatt, H., and Ache, B. W. (2004). Modulation of the olfactory CNG channel by Ptdlns(3,4,5)P3. J. Membr. Biol. 201, 51-57. doi: 10.1007/s00232-004-0707-4

Zhao, Q., Yang, M., Ting, A. T., and Logothetis, D. E. (2007). PIP(2) regulates the ionic current of $\mathrm{P} 2 \mathrm{X}$ receptors and $\mathrm{P} 2 \mathrm{X}(7)$ receptor-mediated cell death. Channels (Austin) 1, 46-55. doi: 10.4161/chan.3914

Conflict of Interest Statement: The authors declare that the research was conducted in the absence of any commercial or financial relationships that could be construed as a potential conflict of interest.

Received: 11 September 2013; paper pending published: 26 September 2013; accepted: 04 November 2013; published online: 25 November 2013.

Citation: Bernier LP, Ase AR and Séguéla P (2013) Post-translational regulation of P2X receptor channels: modulation by phospholipids. Front. Cell. Neurosci. 7:226. doi: 10.3389/fncel.2013.00226

This article was submitted to the journal Frontiers in Cellular Neuroscience.

Copyright (c) 2013 Bernier, Ase and Séguéla. This is an open-access article distributed under the terms of the Creative Commons Attribution License (CC BY). The use, distribution or reproduction in other forums is permitted, provided the original author(s) or licensor are credited and that the original publication in this journal is cited, in accordance with accepted academic practice. No use, distribution or reproduction is permitted which does not comply with these terms. 